\title{
Tsunami Force Reduction due to Obstacle in Front of Coastal Dike and Evaluation of Collision Force by Driftage
}

\author{
Shuhei Ono and Tetsuya Hiraishi \\ Disaster Prevention Research Institute, Kyoto University, Kyoto 612-8235, Japan
}

Received: February 06, 2017 / Accepted: February 13, 2017 / Published: May 31, 2017.

\begin{abstract}
Tsunami caused by the Tohoku earthquake on March 11, 2011 washed away a lot of buildings and deprived many lives on unexpected scale. Seawall is one of the measures to reduce tsunami damage, but itself is also given great damages by tsunami. Study on mechanism of tsunami force acting on seawalls is also quite important and improvement of countermeasures is very important. Hydraulic experiments were conducted to estimate wave force and collision force by driftage due to tsunami on various conditions. The tsunami force reduction due to obstacles installed shoreline is examined and assessed by previous formula. Collision force by driftage due to tsunami is also investigated and assessed by previous formula.
\end{abstract}

Key words: Seawall, tsunami, wave force, obstacle, driftage, collision force.

\section{Introduction}

On March 11, 2011, the Tohoku Earthquake struck off Miyagi Prefecture. The tsunami caused by this earthquake hit a wide area on the coast of the Pacific Ocean and caused serious damage, such as houses running out, collapse of roads and revetment, sliding of breakwaters, particularly from Chiba Prefecture to the coast of Aomori Prefecture. From Fukushima Prefecture to Iwate prefecture, a tsunami with a flooded water level exceeding $15 \mathrm{~m}$ came in Ref. [1].

One of the measures to mitigate the damage caused by the tsunami is setting up a seawall. Juremy Blicker et al. [2] extracted the residents mortality rate and housing destruction rate data of Miyagi prefecture and Iwate prefecture coastal municipalities by the past four major tsunamis of the Meiji Sanriku Tsunami, Showa Sanriku Tsunami, Chile Earthquake Tsunami and Tohoku earthquake tsunami. According to this statistical analysis, it was revealed that a high seawall

Corresponding author: Tetsuya Hiraishi, Ph.D., professor, research field: coastal engineering. of $5 \mathrm{~m}$ above sea level tended to lower the housing destruction rate due to the tsunami. In addition, it has been revealed that mortality rates are also reduced, although slightly, if seawall is present regardless of the height of it.

The usefulness of the seawall is confirmed, but if the seawall itself is damaged, its original function is lost. About $19.5 \%$ of $37.94 \mathrm{~km}$ total extension of the seawall in Iwate Prefecture and Miyagi Prefecture was damaged such as outflow over the massive body, scouring of the ground around the body, collapse and sliding of the body, or these combination effects. In order to avoid the damage, it is necessary to grasp the tsunami force acting on the seawall accurately.

In this experiment, focusing on cracking and sliding among several types of disaster patterns, we investigated the influence of the two types of tsunami forces on the seawall, including the fluid force of the tsunami itself and the collision force when a drifting thrust by the tsunami. With regard to the tsunami wave force acting on the seawall, the tsunami wave force was evaluated using a past formula by changing 
the position of the vertical wall imitating the seawall in the two kinds of landforms slope and upright. In the slope land shape, several types of obstacles were installed in front of the vertical wall. The effect of reducing the tsunami wave force was verified, and the characteristics by each obstacle were considered. Based on these results, we aimed to clarify which obstacles have the most effect of reducing the tsunami wave force.

The collision force was examined under various conditions and compared with the past formula to investigate whether it can be safely and accurately evaluated by those expressions.

\section{Past Study}

The formula suggested by Asakura et al. [3] and Tanimoto [4] (After that, we call these Asakura formula and Tanimoto Formula, respectively) was adopted to valuate wave pressure. Two formulas are shown below respectively.

$$
\begin{gathered}
p=3 \rho g \eta_{\max } \\
p=2.2 \rho g \eta_{\max }
\end{gathered}
$$

where, $p$ is the wave pressure at the bottom of the structure, $\rho$ is the density of water, $g$ is the acceleration of gravity, $\eta_{\max }$ is the maximum run up depth. Asakura Formula is often used to estimate the tsunami wave pressure because it needs only inundation height to calculate. Tanimoto Formula is adopted to estimate the tsunami wave pressure under tsunami design guideline by Ministry of Land, Infrastructure and Transport [5]. In this research, this formula is used by setting inundation zero, however, it is usually used for breakwater installed in the sea. Tanimoto Formula has convenience that it can estimate the tsunami wave force with only inundation height and is commonly used just like Asakura Formula, so we adopted it.

Momentum Formula and the formula suggested by Matsutomi [6] and Ikeno [7] (After that, we call these Matsutomi Formula and Ikeno Formula, respectively) are adopted to estimate collision force. Three formulas are shown below respectively.

$$
\begin{gathered}
F=M v / d t \\
\frac{F}{\gamma D^{2} L}=1.6 C_{M}\left\{v /(g D)^{0.5}\right\}^{1.2} \cdot\left(\sigma_{t} / \gamma L\right)^{0.4} \\
F /(g M)=S \cdot C_{M A} \cdot\left\{v /\left(g^{0.5} D^{0.25} L^{0.25}\right)\right\}^{2.5}
\end{gathered}
$$

where, $F$ is collision force by the driftage, $M$ is mass of the driftage, $v$ is the velocity just before the collision of the driftage, $d t$ is collision action time, $\gamma$ is unit volume weight of the driftage, $D$ (Matsutomi Formula) is diameter of the driftage, $L$ (Matsutomi Formula) is length of the driftage, $C_{M}$ is a mass coefficient, $\sigma_{t}$ is yield stress of the driftage, $S$ is a coefficient, $C_{M A}$ is an added mass coefficient, $D$ (Ikeno Formula) is characteristic length, $L$ (Ikeno Formula) is characteristic length. Momentum Formula sets only the mass of the driftage and the speed just before the collision as parameters and represents a collision in the air. In this study, the apparent mass increases for the water moving together with the driftage, and it is necessary to consider an added mass coefficient. Therefore, we used Matsutomi Formula and the Ikeno Formula that incorporate additional mass as a parameter.

\section{Tsunami Force}

\subsection{Experimental Apparatus}

Fig. 1 shows the outline of the channel in this experiment. The dimensions of the channel are $45.0 \mathrm{~m}$ in length, $1.0 \mathrm{~m}$ in width and $1.5 \mathrm{~m}$ in height. The topography of the vertical wall front is two types of inclination and upright. In the slope topography, the uniform water depth is $64 \mathrm{~cm}$ from the tsunami wave generator to the start point of the gradient, and $1 / 10$ slope with a horizontal distance of $6.4 \mathrm{~m}$ to the land was set up.

In the upright topography, similar to the sloped land shape, a uniform water depth is $64 \mathrm{~cm}$ from the tsunami wave generator to the start point of the gradient, and 1/10 slope with a horizontal distance of $4.9 \mathrm{~m}$ is set. A horizontal part of $1.5 \mathrm{~m}$ from there 


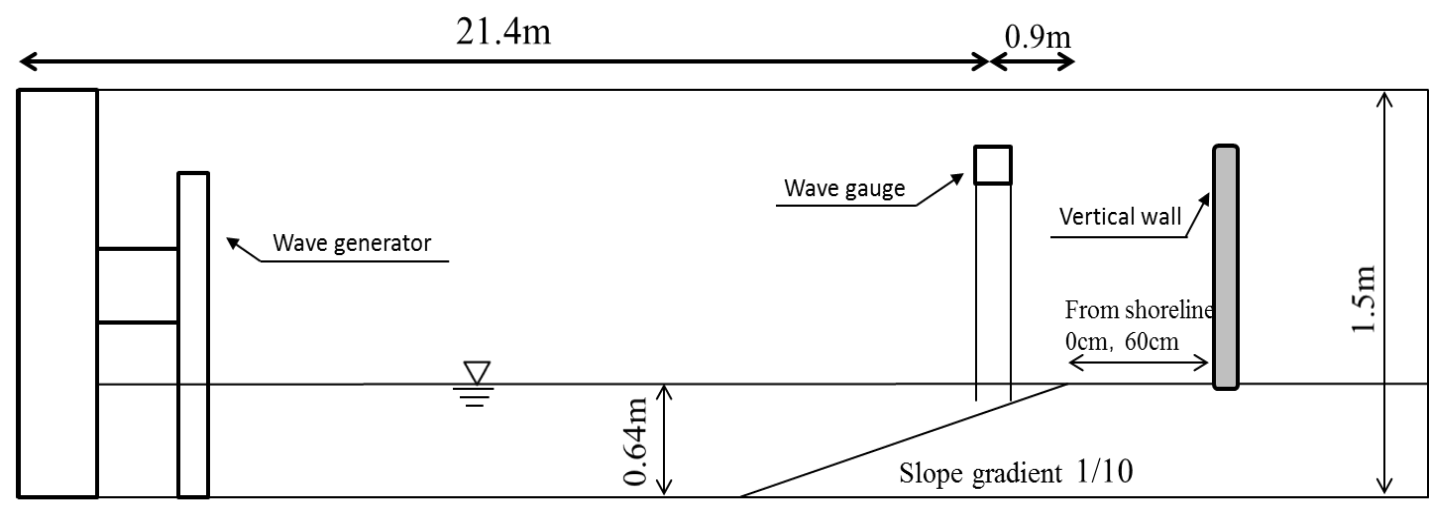

(a) Slope topography

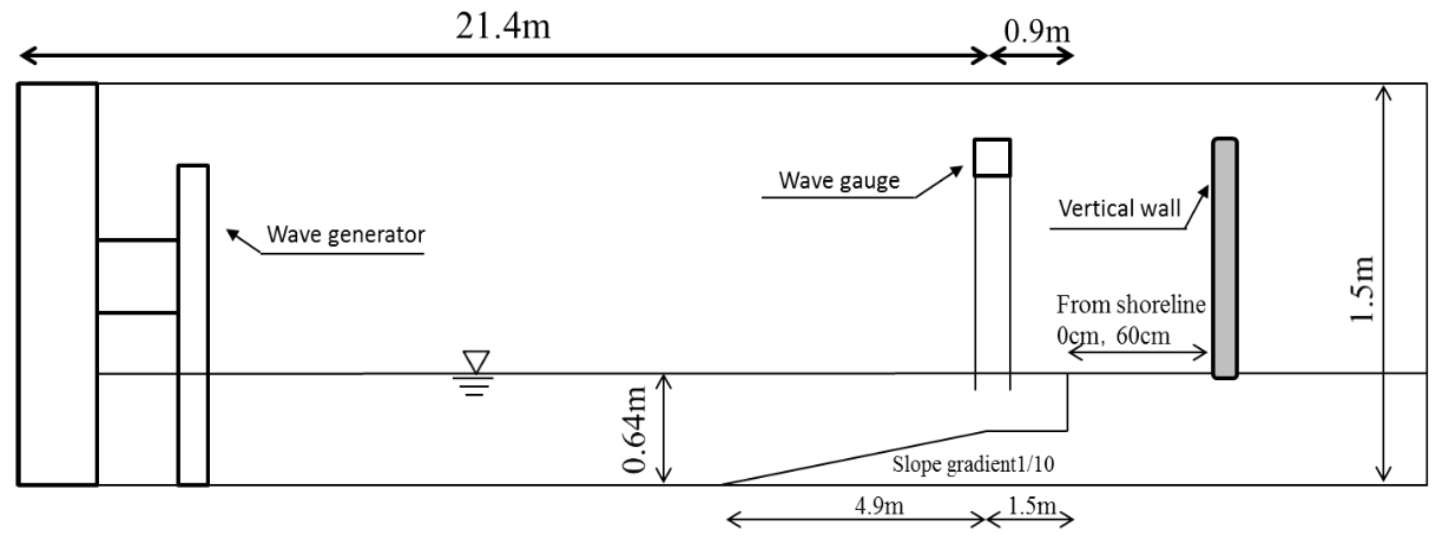

(b) Upright topography

Fig. 1 The outline of experimental channel.

extends to the shoreline. The bottom of the channel is concrete. The topography of the channel is impermeable as it is made of sand and covered with a rubber seat. A solitary wave assumed the first of the tsunami was generated by a piston type wave generator. Two types of stainless steel plates with different heights were used for vertical walls. Both of them are $1.0 \mathrm{~m}$ wide, the same as the channel width. The height of them differs between $1.1 \mathrm{~m}$ and $0.95 \mathrm{~m}$ to distinguish between the wave overtopping and the non-wave overtopping. The scale is supposed to be $1 / 40$ equivalent.

\subsection{Measurement Method}

Both the wave gauge and the wave pressure gauge were measured in the sampling frequency at $20 \mathrm{~Hz}$. The position of the wave pressure gauges installed on the vertical wall is shown in Fig. 2. Line A passes through the center of the vertical wall while Line B is deviated from the center by $10 \mathrm{~cm}$. The experimental value uses the value on Line $A$, and the wave pressure gauges installed on Line B were for the purpose of checking the measurement value for errors. The wave pressure gauges were installed at the position of $5 \mathrm{~cm}, 10 \mathrm{~cm}, 15 \mathrm{~cm}, 20 \mathrm{~cm}, 30 \mathrm{~cm}$ and $50 \mathrm{~cm}$ from the bottom of the vertical wall. Two high-speed cameras were used to observe the fine movement of the wave such as the state of the breaking wave and collision position of the wave front. The frame rate is 3,000 fps.

\subsection{Experimental Result (No Obstacle)}

\subsubsection{Experimental Condition}

The experimental conditions are shown in Table 1. The wave heights of solitary wave are $7 \mathrm{~cm}, 11 \mathrm{~cm}$ and $15 \mathrm{~cm}$. From the analysis with the high-speed 


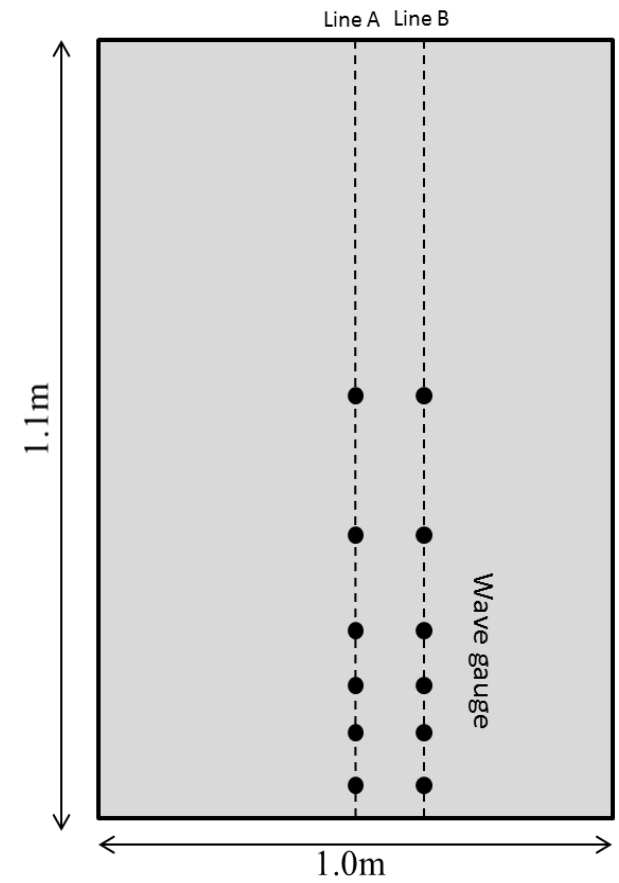

Fig. 2 The position of installed wave pressure gauges.

Table 1 Experimental conditions.

\begin{tabular}{ll}
\hline Wave height $(\mathrm{cm})$ & $7,11,15$ \\
Distance from shoreline $(\mathrm{cm})$ & 0,60 \\
Height of the vertical wall $(\mathrm{m})$ & $1.1,0.95$ \\
Topography & slope, upright \\
\hline
\end{tabular}

camera, it was revealed that the wave height of $15 \mathrm{~cm}$ broke a few-cm front the shoreline and directly hit the bottom of the vertical wall without falling to the ground. In order to evaluate the safety of the sea wall, it is necessary to consider the wave height expected to detect the largest wave force, so we set wave height of $15 \mathrm{~cm}$ to the maximum wave height. For the position of the vertical wall, its height and topography were changed. The measurement was repeated three times in each case, and the average of them was used. By changing the height of the vertical wall, we tried to produce wave overtopping on the one hand and not to on the other hand, but could not distinguish between two vertical walls since the wall of $0.95 \mathrm{~m}$ was too large compared with the maximum wave height of 15 $\mathrm{cm}$. Wave overtopping did not happen. However, the number of data is larger, and the results are more accurate, so we distinguish two vertical walls.

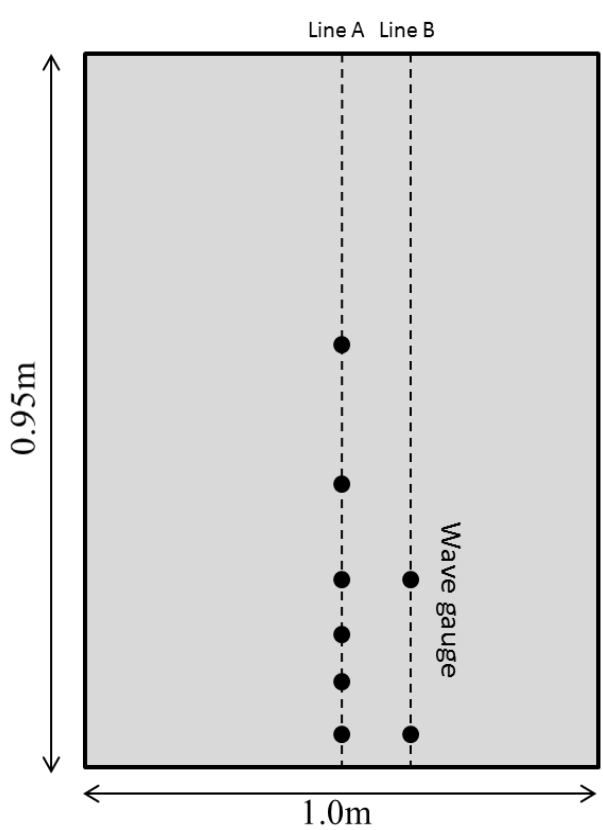

\subsubsection{Experimental Result}

The tsunami wave force per unit width was calculated by integrating the wave pressure from $5 \mathrm{~cm}$ above the bottom of the vertical wall up to $50 \mathrm{~cm}$. The unmeasured part between the wave pressure gauges was complemented with a straight line.

Time series data of each pressure gauge in the case where the vertical wall is installed at the shoreline position in the slope topography are shown in Fig. 3. In the case of a wave height of $7 \mathrm{~cm}$, the impact breaking wave pressure is small. Each wave pressure gauge detects the maximum wave pressure when generating standing wave pressure.

The maximum wave force is generated at this time. In the case of a wave height of $11 \mathrm{~cm}$ and wave height of $15 \mathrm{~cm}$, breaking occurs in front of the vertical wall. Since the tip of the broken wave collides with the bottom of the vertical wall, a large impact breaking wave pressure is detected. However, water mass does not hit the wave pressure gauge installed upper of the vertical wall, only the splash hits, so the wave pressure is small there. Therefore, the wave force is small at the time of wave collision, and the maximum 


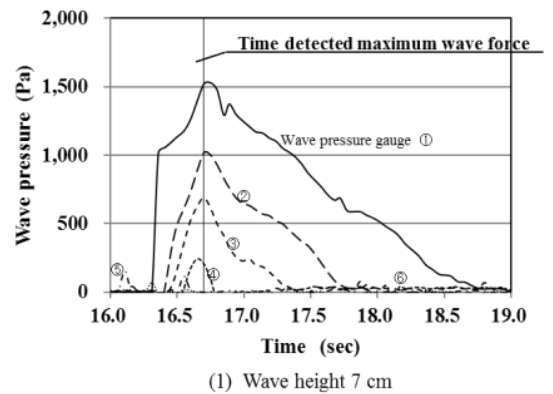

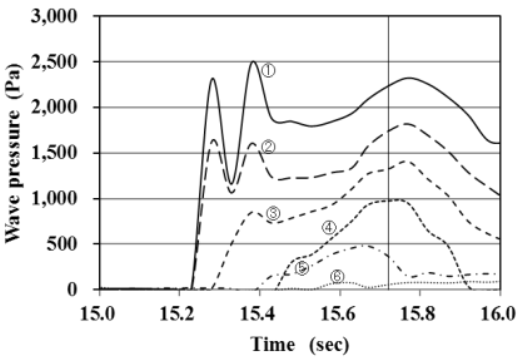

(2) Wave height $11 \mathrm{~cm}$

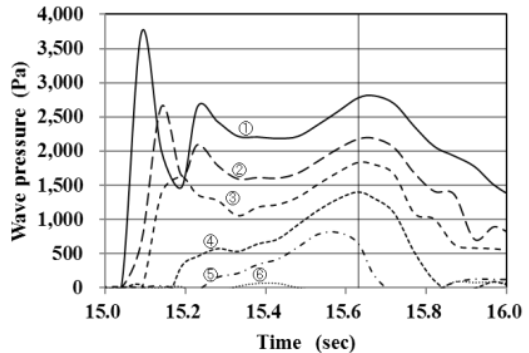

(3) Wave height $15 \mathrm{~cm}$

Fig. 3 Time series data of each wave pressure gauge.

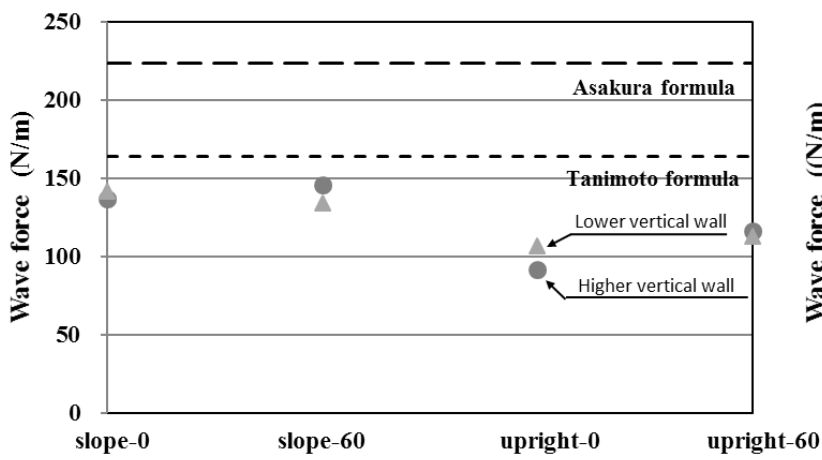

(1) Wave height $7 \mathrm{~cm}$

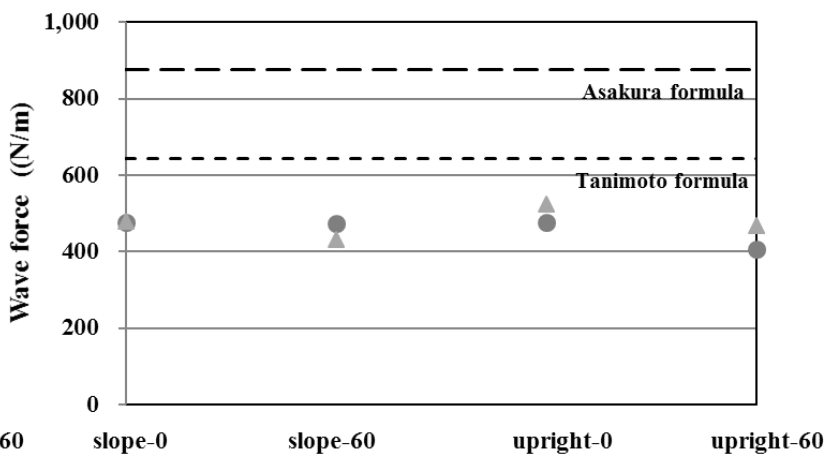

(2) Wave height $11 \mathrm{~cm}$

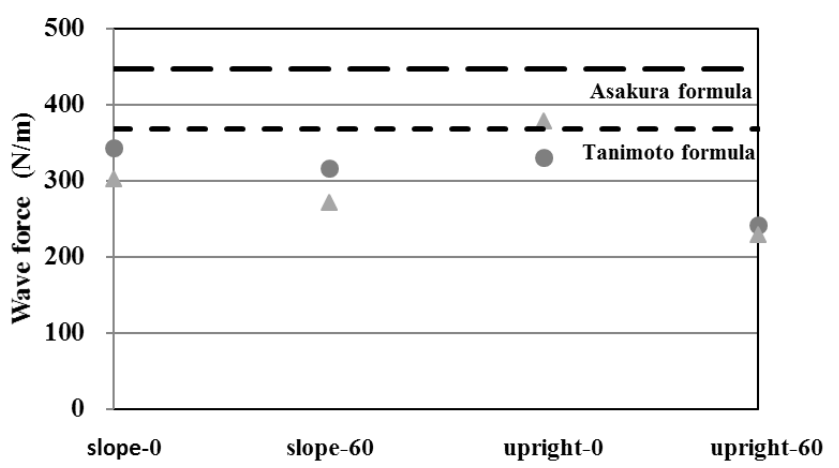

(3) Wave height $15 \mathrm{~cm}$

Fig. 4 Maximum wave force in each case.

wave pressure detected when generating the standing wave pressure like the case with a wave height of 7 $\mathrm{cm}$. Even the case of upright topography and the case where the vertical wall was moved by $60 \mathrm{~cm}$ are similar.

The totally integrated wave force is shown in Fig. 4. The inundation depth used for Tanimoto Formula and Asakura Formula was the average maximum wave height of each case of the wave gauge installed 0.9 off the shoreline. By changing the installation position of the vertical wall, a difference of $100 \mathrm{~N}$ in the upright topography with a wave height of $11 \mathrm{~cm}$ appeared but the difference was not large in other cases. It was less than the wave force calculated by Tanimoto Formula in most cases and it was found that the wave force can be evaluated well by Tanimoto Formula.

\subsection{Experimental Result (Obstacle)}

\subsubsection{Experimental Condition}

Experimental conditions are shown in Table 2. Since obstacles are placed at the shoreline, it is impossible to place the vertical wall there. The 
Table 2 Experimental conditions.

\begin{tabular}{ll}
\hline Wave height $(\mathrm{cm})$ & $7,11,15$ \\
Distance from shoreline $(\mathrm{cm})$ & 30,60 \\
Height of the vertical wall $(\mathrm{m})$ & 1.1 \\
Topography & Slope \\
Obstacle & A, B, C, D, E \\
\hline
\end{tabular}

vertical wall was moved $30 \mathrm{~cm}$ behind the shoreline, and its case compared with the case where the vertical wall were installed at the shoreline and obstacles were not installed. There are 5 obstacles. Obstacle types are shown in Photograph 1. Each experimental model consists of two kind materials, wood and artificial resin material used for dissipating wave. The wood is assumed to be a sand hill, and the artificial resin a coastal forest.

\subsubsection{Experimental Result}

The maximum wave force is shown in Fig. 5 together with the wave force calculated by Tanimoto Formula. The wave force calculated by Asakura Formula is not included in the graph because experimental value was less than the wave force calculated by Tanimoto Formula.

Compared with the case without the obstacle, it is confirmed that the effect of reducing the wave force appears in all the obstacle cases. The effect of reducing the wave force was estimated to be the influence of air mixing due to wave disturbance and reflection by obstacles. Wave disturbance is caused by collision of the tip of broken wave with an obstacle or by transmission through an artificial resin. The wave contains air bubbles causing that the standing wave pressure decreases or the peak of each wave pressure gauge deviates. From the time series data of cases with a wave height of $15 \mathrm{~cm}$, and the vertical wall set at $30 \mathrm{~cm}$ moved behind the shoreline (Fig. 6), it is confirmed that the experimental values of each pressure gauge are undulating and unstable, and the peak of them is deviated when the maximum wave force is detected. It was also observed that a large amount of air was contained in the wave after colliding with the obstacle from the high-speed camera. Reflection by obstacle means that some parts of waves reflect at the obstacle, and the amount of water flowing into the land becomes smaller. It was observed that when an obstacle was not installed, the wave shaped like one raised mountain reflected at the

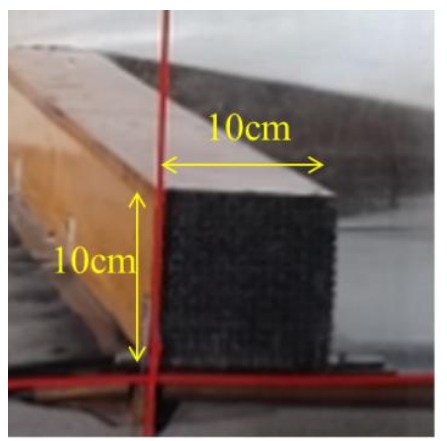

(1) Obstacle A (wood)

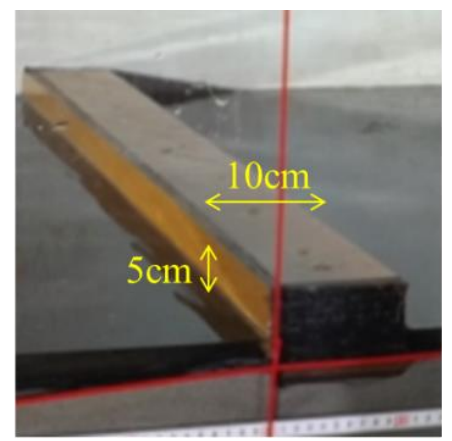

(2) Obstacle B (wood)

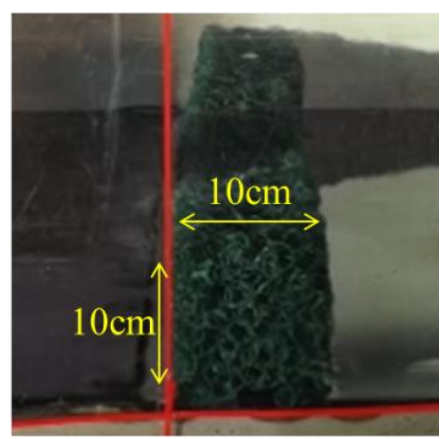

(3) Obstacle C (artificial resin)

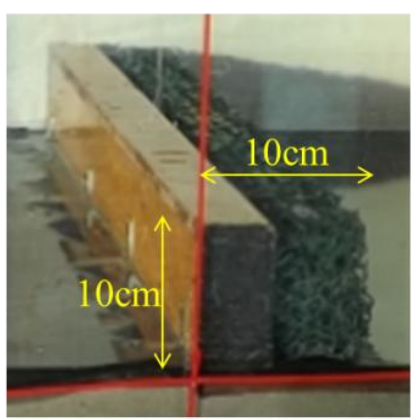

(4) Obstacle D (wood + artificial resin)

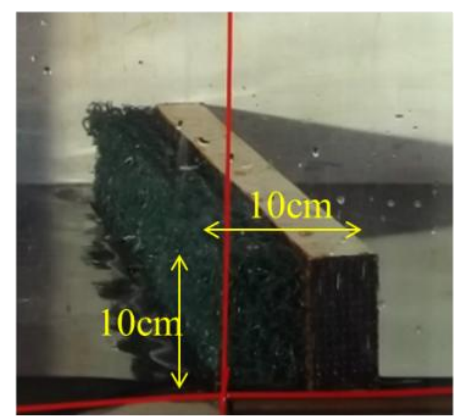

(5) Obstacle E (wood + artificial resin)

Photograph 1 Obstacles installed in front of the vertical wall (left: open sea, right: land). 


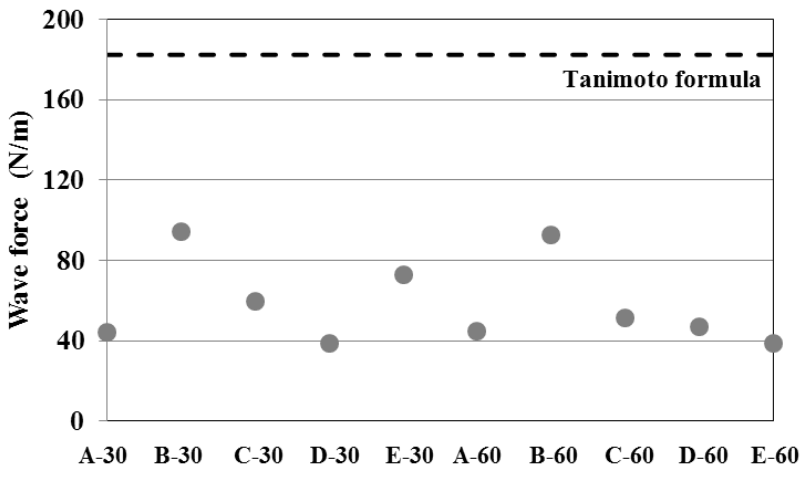

(1) Wave height $7 \mathrm{~cm}$

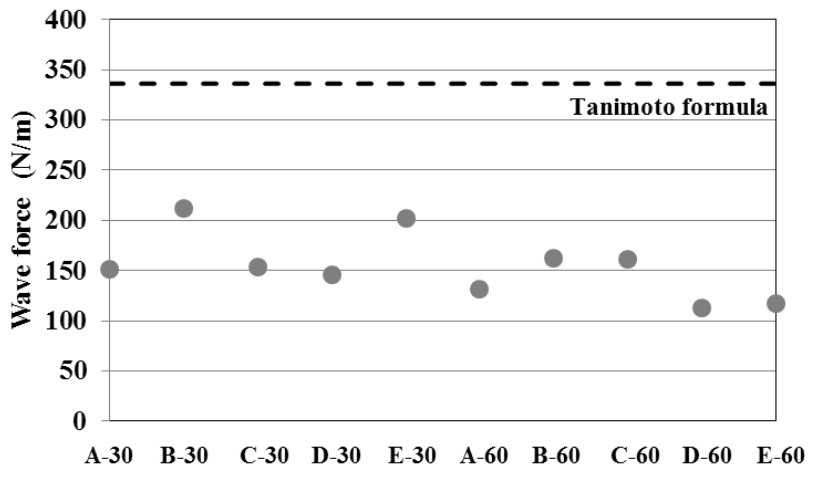

(2) Wave height $11 \mathrm{~cm}$

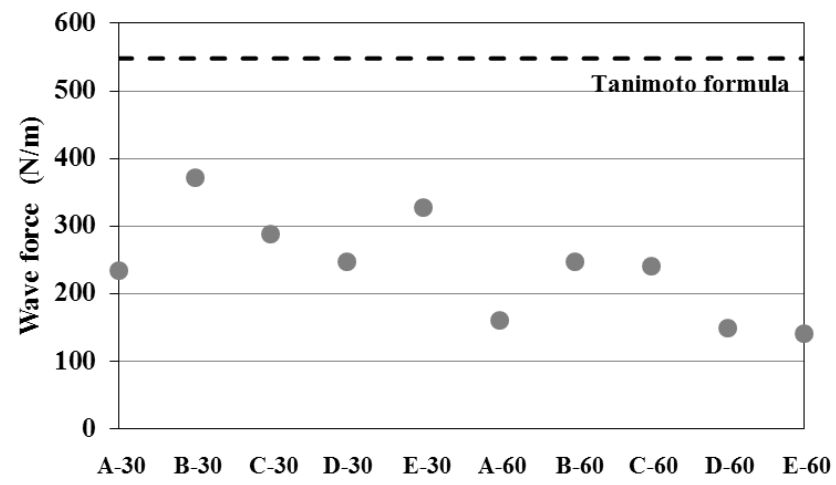

(3) Wave height $15 \mathrm{~cm}$

Fig. 5 Maximum wave force in each case.

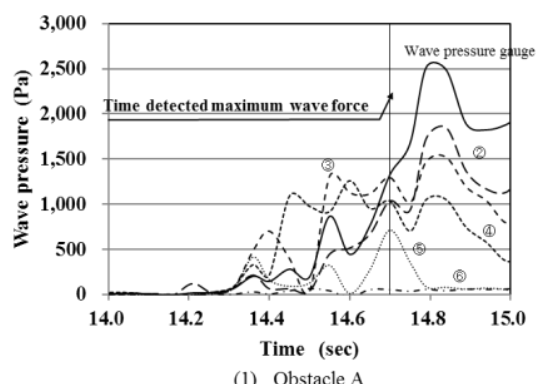

(1) Obstacle A

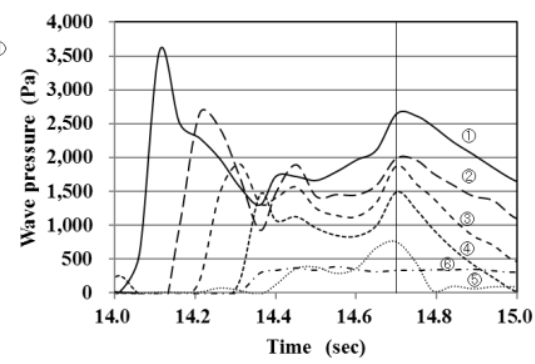

(2) Obstacle B

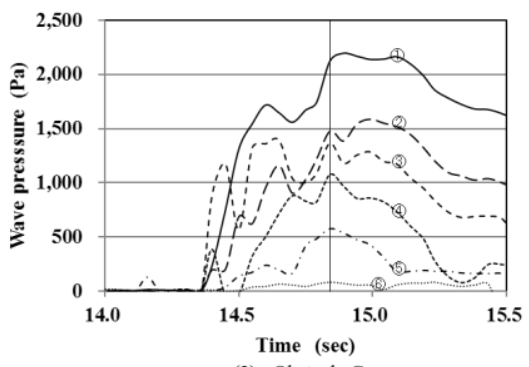

(3) Obstacle C
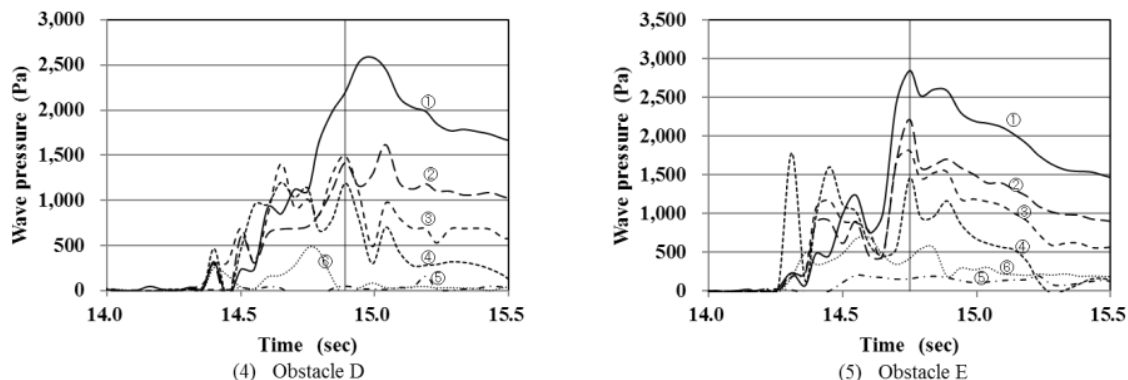

Fig. 6 Time series data of each wave pressure gauge $(30 \mathrm{~cm}$ from shoreline).

vertical wall and returned to the offshore keeping the same shape from the high-speed camera. However, when installing obstacles, it was observed that solitary waves in the shape of one mountain returned to the offshore as two mountains. This indicates that it was reflected by an obstacle besides the vertical wall. 
In the case of installing the vertical wall $30 \mathrm{~cm}$ behind the shoreline, the wave force was detected slightly larger in the case of the Obstacle B than others. Since Obstacle B is only $5 \mathrm{~cm}$ lower than others, the rate of broken wave getting over the obstacle becomes large, and the disturbance due to the collision with the obstacle becomes small. The rate of reflection also decreases.

The time series data of each wave pressure gauge in the cases with a wave height of $15 \mathrm{~cm}$ and installing the vertical wall moved $60 \mathrm{~cm}$ behind the shoreline are shown in Fig. 7. Compared with cases where the vertical wall is installed $30 \mathrm{~cm}$ behind the shoreline (Fig. 6), the time series data of each wave pressure gauge are not so undulating. It was confirmed that bubbles escaped in the process of going upstream by the high-speed camera. Therefore, the wave force reduction effect due to disturbance was considered small. We considered that the influence of reflection much more greatly contributes to the reduction of wave force than that of disturbance. In the case for Obstacle B or Obstacle C, it was considered that the wave force was detected slightly larger than the other obstacles due to the obstacle height and permeability.

\section{Collision Experiment}

\subsection{Experimental Apparatus}

We used two models simulating driftwood and ship as a driftage. They were shown in Photographs 2 and 3. Since the driftwood model has a small collision area, three models were used to raise the probability of collision. One of them is $20 \mathrm{~g}$ and others are $19 \mathrm{~g}$. Since the ship model has a large collision area and collision force can be easily measured, only one model was used. The weight is $80 \mathrm{~g}$. The driftwood and the ship model are made of wood. In order to prevent mass fluctuation due to water absorption, waterproof coating was applied to the surface of them. The driftwood model was made of tropical Ramin wood, and the ship model was made of the northern American wood. The detection of the collision force was performed with the load cells. The model did not collide a lot because the measurement part at the center of them is small relative to its own area. Accordingly, it was measured by using a device (Photograph 4) for increasing the probability of detection of collision force. Load cells are affixed to acrylic, and a supporting rod attached an iron plate is

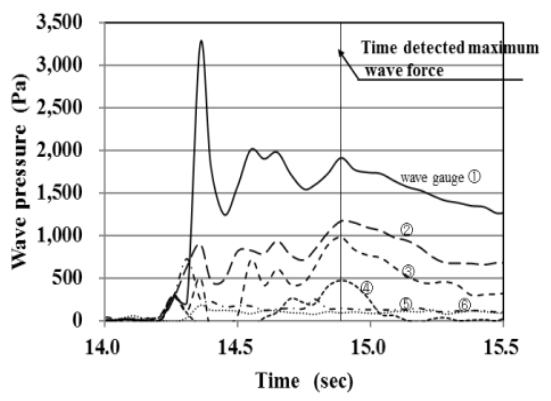

(1) Obstacle A

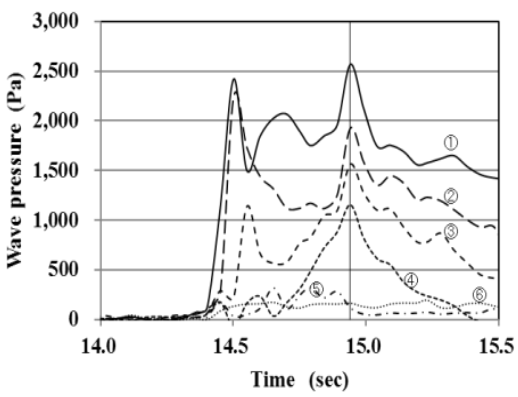

(2) Obstacle B

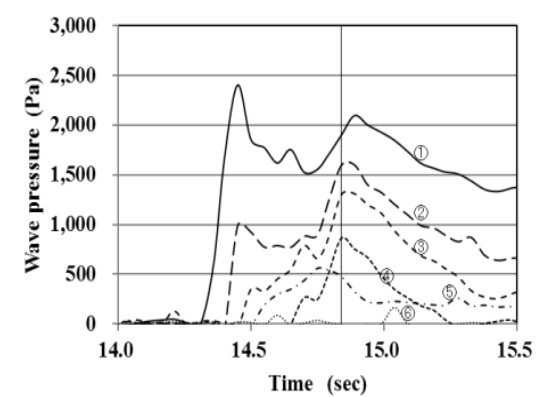

(3) Obstacle $\mathrm{C}$

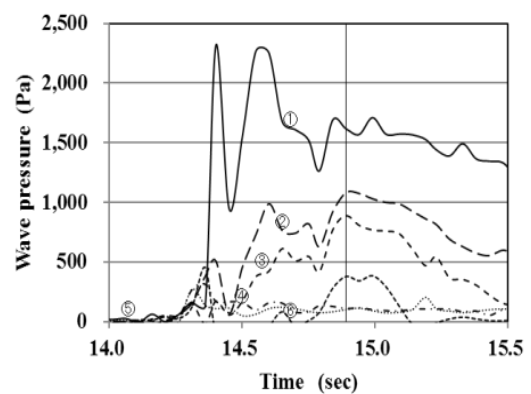

(4) Obstacle D

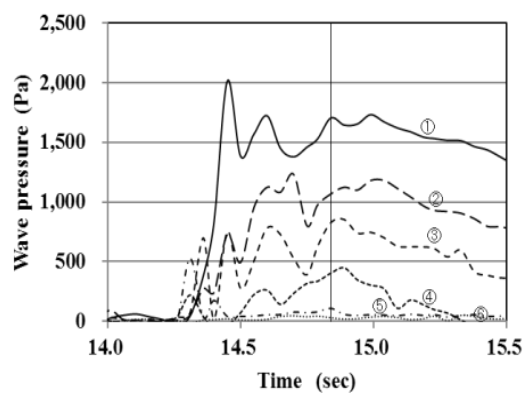

(5) Obstacle E

Fig. 7 Time series data of each wave pressure gauge $(60 \mathrm{~cm}$ from shoreline). 


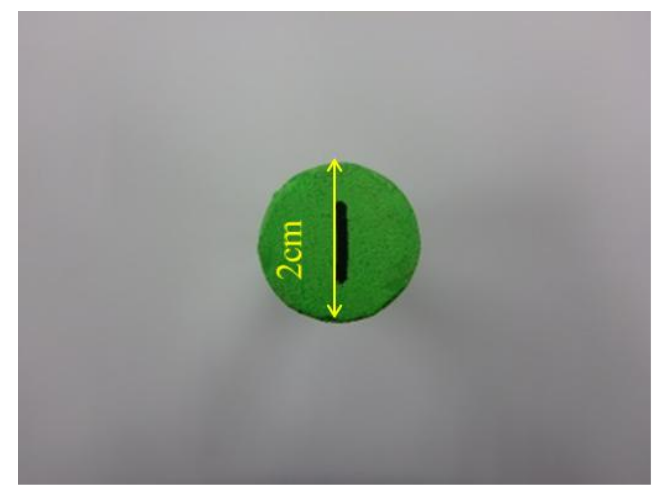

(1) Cross sectional view

Photograph 2 Drift wood model.

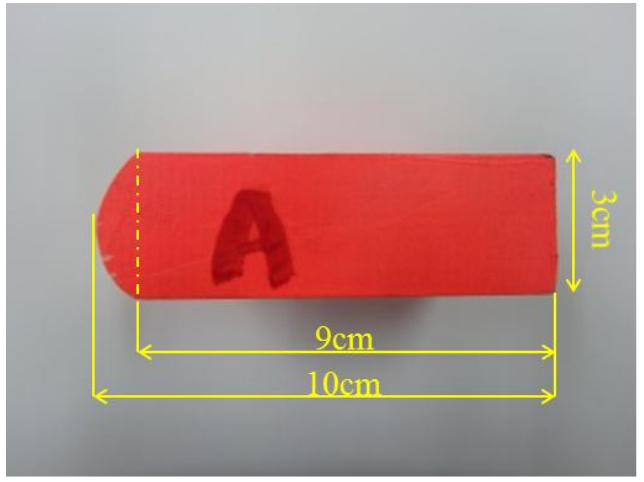

(1) Cross sectional view

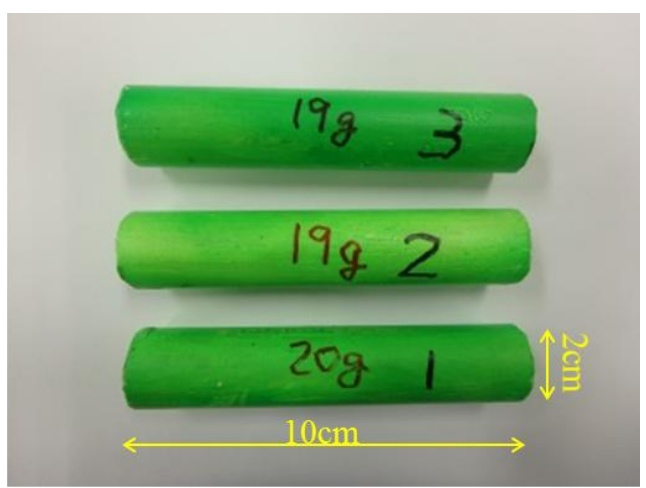

(2) Plane view

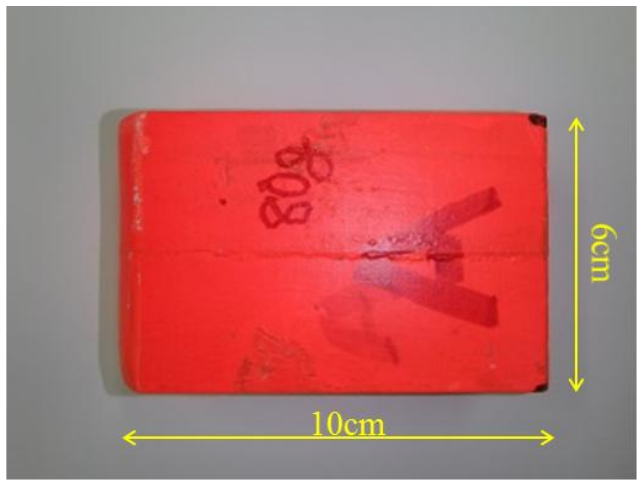

(2) Plane view

Photograph 3 Ship model.

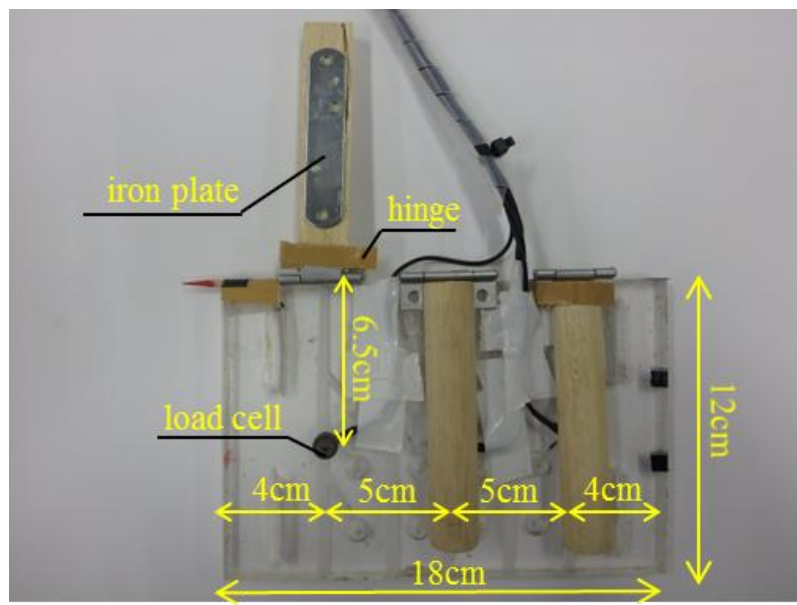

Photograph 4 Device for increasing probability of collision.

set so as to cover over load cells. It indirectly transmits a collision force to the center of the load cell via the rod.

\subsubsection{Measurement Method}

In order to precisely collide with the equipment, we decided the initial installation position. Models were set on bamboo skewers or golf tees inserted in the bottom of the channel in order to keep initial position of them. The collision force was measured at the sampling frequency of the load cell at $20 \mathrm{~Hz}$.

4.1.2 Experiment Condition

Experiment conditions are shown in Table 3. We 
Table 3 Experimental conditions.

\begin{tabular}{ll}
\hline Wave height $(\mathrm{cm})$ & $7,11,15$ \\
Distance from shoreline $(\mathrm{cm})$ & 30,60 \\
Height of the vertical wall $(\mathrm{m})$ & 1.1 \\
Topography & slope \\
Drifting model & driftwood, ship \\
\hline
\end{tabular}

tried at least three times in each case. Although the initial installation position was determined and the apparatus was used, the rate of undetectable was about once every 5 times. Trials of undetectable were not redone and not included. The average of the values measured in 3 trials was taken as representatives.

\subsubsection{Experimental Result}

The yield stress of wood is almost the same as the compressive strength [5], when collision force of a driftwood model was calculated by Matsutomi Formula, compressive strength was used instead. That of Ramin is $67 \mathrm{MPa}$ [7].

The collision force calculated by Matsutomi Formula was 5 to 6 times the measured value. It was an overvaluation, so we adopted the mass coefficient according to the experimental conditions of this experiment. The mass coefficient varies with opening degree. Opening degree means width of the vertical wall relative to channel width. In the experiment of Matsutomi, the mass coefficient is proportional to the opening degree to $40 \%$, and it is constant after $40 \%$. The mass coefficient of the Matsutomi Formula is 1.7 assuming the most dangerous case. In this experiment, the width of the channel and the vertical wall are in agreement, so the opening degree is $0 \%$. The mass coefficient corresponding to the opening degree of $0 \%$ is 0.5 , and it is set to 0.5 .

Collision forces in each case of the driftwood model are shown in Fig. 8. The value calculated by Ikeno Formula and momentum formula is smaller than the experimental value. The momentum formula is used in the air, and does not consider the influence of water. However, the apparent mass increases with the amount of fluid. Therefore, it is considered that the mass in the momentum formula becomes underestimation and it is smaller than the measured value.
In the experiment of Ikeno, the tsunami is generated by rapidly opening the gate, and a drifting model is set $80 \mathrm{~cm}$ in front of the vertical wall. According to the experiment of Ikeno, driftage collided during or after the collision of the surge. On the other hand, in this experiment, a solitary wave is generated using the piston type wave generator, and driftage is set about 7 $\mathrm{cm}$ to $60 \mathrm{~cm}$ in front of vertical wall, so driftage collided almost simultaneously with the tip of wave. It is considered that the amount of fluid moving with the driftage is larger and the added mass accordingly increases. Furthermore, since the driftage collides with the tip of the wave, the influence of the buffering function by the fluid is smaller in this experiment. Because of them, we estimated that the experimental value was larger than Ikeno Formula. When evaluating using Matsutomi Formula, since the experimental value is included and close, we thought that it is suitable for evaluating collision.

The collision force in each case of the ship model is shown in Fig. 9. The value calculated by two formulas

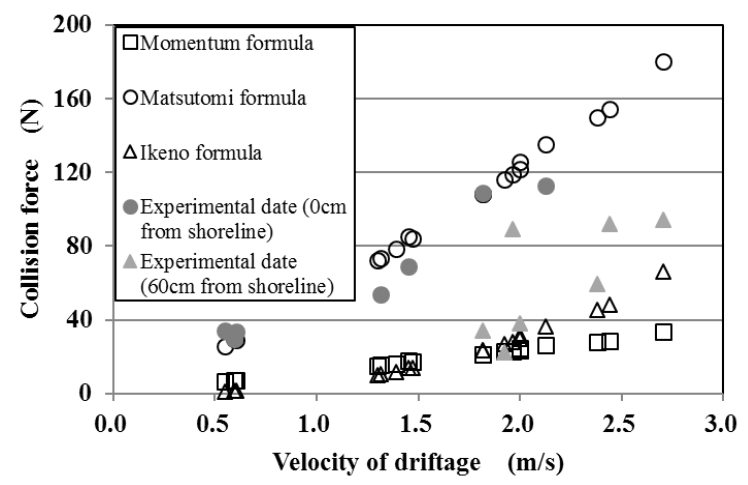

Fig. 8 Collision force by driftage wood model.

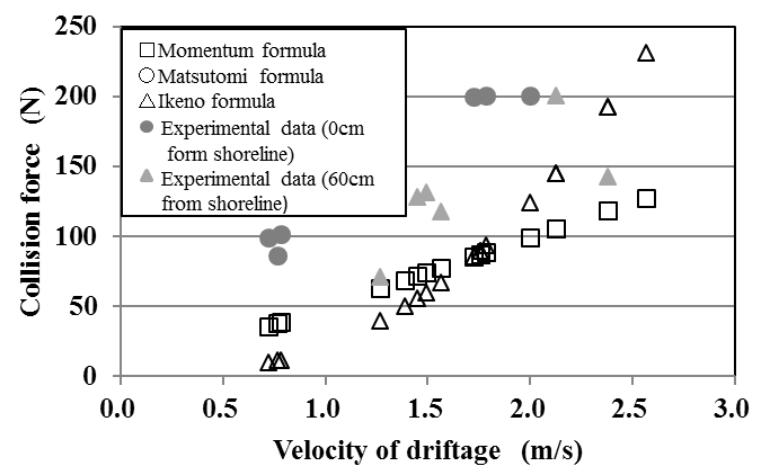

Fig. 9 Collision force by ship model. 
was smaller than the measured value and was not suitable. It is considered that value by the two formulas became smaller than the experimental value for the same reason as the driftwood model.

\section{Conclusions}

- When the obstacle was not installed, the wave force acting on the vertical wall was able to be safely evaluated by Tanimoto's Formula regardless of the installation of the vertical wall in both the inclined and upright topography.

- Tsunami wave force is reduced by wave disturbance and reflection due to obstacles.

- The higher the obstacle is, the greater the reduction effect of the tsunami force becomes. Among the obstacles of the same height, the Obstacle A, Obstacle D and Obstacle E have large reduction effect because of low permeability.

- The collision force of the driftwood model could be evaluated by the Matsutomi formula after converting the opening degree according to the experimental condition.

- The collision force by the Ikeno formula was underestimated because the buffering function of the fluid is smaller and the added mass is larger than this experiment due to the difference between the method of wave generation and the model installation position.

\section{References}

[1] Hiraishi, T., Yoneyama, N., Baba, Y., Mori, N., Azuma, R., Yasuda, T., and Mase, H. 2011. "Initial Field Survey on Coastal Hazard in Miyagi-Prefecture due to 2011 Tohoku Earthquake Tsunami." Journal of Japan Society of Civil Engineers, Ser. B2 (Coastal Engineering) 67 (2): 1306-10.

[2] Nateghi, R., Bricker, J. D., Guikema, S. D., and Bessho, A. 2016. "Statistical Analysis of the Effectiveness of Seawalls and Coastal Forests in Mitigating Tsunami Impacts in Iwate and Miyagi Prefectures." PLoS One 11 (8): e0158375.

[3] Asakura, R., Iwase, K., Ikeya, T., Takao, M., Kaneto, T., Huji, N., and Omori, M. 2000. "An Experimental Study on Tsunami Force Overflowing the Bulkhead." Coastal Engineering Journal 47: 911-5.

[4] Ministry of Land, Infrastructure, Transport and Tourism, Bureau of Port and Harbor. 2013. Guideline for Tsunami-Resistant Design of Breakwaters.

[5] Matsutomi, H. 1999. "A Practical Formula for Estimating Impulsive Force due to Driftwood and Variation Features of the Impulsive Force." Journal of JSCE No. 621/II-47: 111-27.

[6] Ikeno, M., and Tanaka, H. 2003. "An Experimental Study on Tsunami Running up and Collision by Driftage." Coastal Engineering Journal 50: 721-5.

[7] Japan Wood Products Information \& Research Center. Types and Characteristics of Wood. Accessed January 12, 2016. http://jawic.or.jp/woods/sch.php?nam0=ramin. 